\title{
Target Drug Exposure Attainment in Children: How to Get from Better to Best
}

\author{
Robert B. Flint ${ }^{1,2}$ (D) Karel Allegaert ${ }^{2,3,4}$
}

Published online: 8 June 2020

(c) The Author(s) 2020

\section{Introduction}

The maturational physiology of children is reflected in more complex dosing regimens to attain target exposure throughout pediatric life [1]. For multiple drugs, therapeutic drug monitoring (TDM) may support the optimization of pharmacotherapy if the following requirements are met: (1) a narrow therapeutic range, (2) a large variability, (3) a known concentration-effect relationship, and (4) absence of measurable effect. Model-informed precision dosing (MIPD), the next step for TDM, has recently gained more attention as it may serve as a powerful tool to help individualize dosing [2]. In particular, pediatric pharmacotherapy may benefit from the development of such clinical decision support (CDS) and move beyond complex dosing regimens to even more personalized dosing.

In this issue of the journal, Hartman et al. [3] evaluate target attainment during TDM of vancomycin, gentamicin, and tobramycin dosed according to model-based dosing guidelines for critically ill neonates and children. Despite this, the authors still observed a large proportion of both sub- and supratherapeutic concentrations for all three drugs. We very much appreciate their initiative in evaluating target attainment following the implemented simplification of the more

This comment refers to the article available at https://doi. org/10.1007/s40272-020-00400-8.

Karel Allegaert

karel.allegaert@uzleuven.be

1 Department of Pediatrics, Division Neonatology, Erasmus University Medical Center, Rotterdam, The Netherlands

2 Department of Pharmacy, Erasmus University Medical Center, Rotterdam, The Netherlands

3 Department of Development and Regeneration, p/a Neonatal Intensive Care Unit, UZ Leuven, Herestraat 49, 3000 Leuven, Belgium

4 Department of Pharmaceutical and Pharmacological Sciences, KU Leuven, Leuven, Belgium complex dosage regimen suggested in the published population pharmacokinetic (PK) models $[4,5]$. Their elegant design using data collected for TDM may be an inspiration for improved evaluation of pharmacotherapy for other drugs, as no additional burden was needed.

In this commentary, we would like to stress that such efforts are-at best - part of a target exposure improvement approach: how do we get from better to best? This relates to the "best target selection" and "best target attainment."

\section{Selection of the Best Target}

Hartman et al. [3] used vancomycin trough concentrations as a surrogate target for an area under the plasma concentration-time curve (AUC) $)_{0-24 \mathrm{~h}}>400$ to determine adequate therapy, although the target trough corresponding to an AUC $0-24 \mathrm{~h}$ of 400 depends on the dosing interval and individual clearance [6]. Allegaert et al. [7] illustrated that a certain daily dose for an AUC of $400_{0-24 \mathrm{~h}}$ divided by 12-, 8-, and 6-h intervals corresponds to a trough steady state concentration of 11.3, 13.0, and $14.0 \mathrm{mg} / \mathrm{L}$, respectively. Model-based estimations using Bayesian forecasting per patient would have allowed an evaluation based on $\mathrm{AUC}_{0-24 \mathrm{~h}}$ instead of the surrogate target (trough concentrations). Nevertheless, the recommended vancomycin dosing regimen from the modelers did use $\mathrm{AUC}_{0-24 \mathrm{~h}}>400$ as a target [4].

For aminoglycosides, a peak concentration of 8-10 times the minimum inhibitory concentration is considered the target for effectiveness, and a trough concentration $<1 \mathrm{mg} / \mathrm{L}$ (gentamicin) is the target for toxicity. Hartman et al. [3] retrospectively collected data on drug administrations and peak and trough concentrations from electronic health records. The inaccurate registration of actions in clinical practice, such as exact time and duration of drug administration or sample collection, has a large impact on the quality and subsequent interpretation of data. Given the rapidly changing concentration around time of peak concentration, errors in 
registered collection times of $\geq 10$ min have a large impact on the accuracy of interpretation. Evaluation of aminoglycoside toxicity based on collected trough concentrations may lead to adjusted dose intervals. De Hoog et al. [8] determined that the dose interval may be up to $48 \mathrm{~h}$ with maintained effectiveness so long as an adequate peak concentration is reached. However, the model-based dosing regimens by Valitalo et al. [5] suggested 60- and 72-h intervals for preterm neonates up to 10 days postnatal age and low birthweight $<2 \mathrm{~kg}$. As the effectiveness of dose intervals $>48 \mathrm{~h}$ has not been investigated, TDM should be used to explore possible shortening of the dose interval to $\leq 48 \mathrm{~h}$.

The study cohort of Hartman et al. [3] was limited because of the criterion to include patients with samples collected at desired timepoints for peak or trough concentration and when steady state is reached. The combination of both allows straightforward comparison with reference target ranges. Therefore, 923 of 1642 patients were excluded as the measured concentration could not directly be compared to the target concentrations. The use of Bayesian forecasting based on the measured concentrations in each patient (i.e., by estimating the trough concentration where a sample was collected too early) would have allowed the inclusion of more patients and the use of better targets for effectiveness for vancomycin ( $\mathrm{AUC}_{0-24 \mathrm{~h}}$ instead of trough concentrations).

Hartman et al. [3] considered steady state to be achieved 3 half-lives after treatment start instead of 4-5 half-lives, as generally accepted. This may have overestimated the proportion of subtherapeutic concentrations of vancomycin. Furthermore, steady state was based on the estimated halflives of vancomycin for infants and neonates described by Gross et al. [9] and De Hoog et al. [10], where clearance was only found to be predicted by postnatal age. Besides postnatal age, Janssen et al. [4] and Valitalo et al. [5] determined birthweight as a relevant covariate for clearance, which is in accordance with physiological intra- and extrauterine maturation. Hartman et al. [3] may have considered these more sophisticated descriptions of clearance for steady state determination, at least for (preterm) neonates.

\section{Best Target Attainment}

\subsection{Model Translation to Dosages Fails to Catch the Full Spectrum}

The Dutch Pediatric Formulary dosages for vancomycin, gentamicin, and tobramycin evaluated by Hartman et al. [3] were simplifications of the suggested dosages in the modeling papers. However, the number of bodyweight-based dosage categories was reduced to arbitrary dichotomous suggestions (such as a given weight or age range), leading to larger ranges and variability in measured exposure.
Furthermore, the suggested loading dose for vancomycin is not yet incorporated in the Dutch Pediatric Formulary. In particular, the smallest infants, and patients with renal impairment, have low clearance so require the most time to reach adequate exposure without a loading dose. We are aware that such simplification of dosing regimens may reduce prescribing errors and the risk of forgetting a dose adjustment for maturational effects, but therapy may be suboptimal. Unfortunately, hardly any electronic prescribing systems can currently incorporate complex dosing regimens and guide programmed dose adjustments on patient characteristics reflecting maturation or disease progression. Safe and effective pharmacotherapy for children urgently demands the development and integration of software to accurately prescribe and adjust dosages and to incorporate MIPD and CDS.

Besides simplifications to facilitate clinical use of dosing regimens, omission of specific patient categories is relevant. As discussed by Hartman et al. [3], the population PK model by De Cock et al. excluded patients with severe renal dysfunction. Therefore, the subsequent dosing regimens may not be applied to patients with severe renal dysfunction. Although hemofiltration was an exclusion criterion for the cohort of Hartman et al. [3], patients with severe renal dysfunction were included and may have been responsible for the highest exposure and trough concentrations.

\subsection{Model-Informed Precision Dosing as the Road Ahead}

MIPD can serve as a powerful tool to help individualize dosing [2]. Bedside presentation of combined data on exposure and effect would allow quick/real-time individualization of dosing and target attainment. Frymoyer et al. [11] reported a successful adaptation of an incorporated Bayesian forecasting tool for CDS on vancomycin therapy within the electronic health record. Unfortunately, such integration in electronic health records is currently only in development [12]. Using integrated CDS will minimize data translation errors, and data of predictors for the PK or pharmacodynamics may be continuously translated to suggested pharmacotherapy adjustments (e.g., creatinine for aminoglycosides and vancomycin, postnatal age for maturational effect, interacting comedication such as nonsteroidal anti-inflammatory drugs on vancomycin clearance) [13]. This would require reliable registered data of clinical care, which may be achieved using scanning, automated checks, and bi-directional data transfer.

Clinical (pediatric) pharmacology is a multidisciplinary data science field that utilizes mathematical and statistical methods to generate maximal knowledge from data [14]. Pharmacometrics is a well-recognized tool to characterize disease progression, pharmacokinetics, and risk factors and can be incorporated in MIPD. Future research and 
implementation initiatives should focus on the feasibility of integrating tools for model-informed individualized dosing in clinical practice.

Immediately implementable improvements may be to collect early samples upon start of treatment that can be forecasted using MIPD and allow prediction of an individual dosing regimen to attain steady state exposure within the target range. This would enable early optimization of treatment. For vancomycin, a trough sample may be collected before the second dose (even if the first dose was a loading dose) and targeted for $\mathrm{AUC}_{0-24 \mathrm{~h}}>400$ using Bayesian forecasting. At the start of aminoglycoside therapy, sample collection depends on the situation. A sample may be drawn either a few hours before the next dose to predict a safe trough before continuation. We strongly recommend that all stakeholders embrace this opportunity to further tailor pharmacotherapy to the individual needs of our patients as an opportunity to "get from better to best."

\section{Compliance with Ethical Standards}

Conflicts of interest Robert B. Flint and Karel Allegaert have no conflicts of interest that are directly relevant to the content of this article.

Funding No sources of funding were used to conduct this study or prepare this manuscript. Open Access funding was provided by the Netherlands Read and Publish (Springer Compact) agreement.

Open Access This article is licensed under a Creative Commons Attribution-NonCommercial 4.0 International License, which permits any non-commercial use, sharing, adaptation, distribution and reproduction in any medium or format, as long as you give appropriate credit to the original author(s) and the source, provide a link to the Creative Commons licence, and indicate if changes were made. The images or other third party material in this article are included in the article's Creative Commons licence, unless indicated otherwise in a credit line to the material. If material is not included in the article's Creative Commons licence and your intended use is not permitted by statutory regulation or exceeds the permitted use, you will need to obtain permission directly from the copyright holder. To view a copy of this licence, visit http://creativecommons.org/licenses/by-nc/4.0/.

\section{References}

1. van den Anker J, Reed MD, Allegaert K, Kearns GL. Developmental changes in pharmacokinetics and pharmacodynamics. J Clin Pharmacol. 2018;58(Suppl 10):S10-25. https://doi. org/10.1002/jcph.1284.

2. Keizer RJ, Ter Heine R, Frymoyer A, Lesko LJ, Mangat R, Goswami S. Model-informed precision dosing at the bedside: scientific challenges and opportunities. CPT Pharmacometr Syst Pharmacol. 2018;7(12):785-7. https://doi.org/10.1002/ psp4.12353.

3. Hartman SJF, Orriens LB, Zwaag SM, et al. External validation of model-based dosing guidelines for vancomycin, gentamicin and tobramycin in critically ill neonates and children-a pragmatic two-center study. Pediatr Drugs. 2020. https://doi.org/10.1007/ s40272-020-00400-8.

4. Janssen EJ, Valitalo PA, Allegaert K, de Cock RF, Simons SH, Sherwin CM, et al. Towards rational dosing algorithms for vancomycin in neonates and infants based on population pharmacokinetic modeling. Antimicrob Agents Chemother. 2016;60(2):101321. https://doi.org/10.1128/AAC.01968-15.

5. Valitalo PA, van den Anker JN, Allegaert K, de Cock RF, de Hoog M, Simons SH, et al. Novel model-based dosing guidelines for gentamicin and tobramycin in preterm and term neonates. J Antimicrob Chemother. 2015;70(7):2074-7. https://doi.org/10.1093/ $\mathrm{jac} / \mathrm{dkv} 052$.

6. Tkachuk S, Collins K, Ensom MHH. The relationship between vancomycin trough concentrations and AUC/MIC ratios in pediatric patients: a qualitative systematic review. Paediatr Drugs. 2018;20(2):153-64. https://doi.org/10.1007/s40272-018-0282-4.

7. Allegaert K, Flint R, Smits A. Pharmacokinetic modelling and Bayesian estimation-assisted decision tools to optimize vancomycin dosage in neonates: only one piece of the puzzle. Expert Opin Drug Metab Toxicol. 2019;15(9):735-49. https://doi. org/10.1080/17425255.2019.1655540.

8. de Hoog M, Mouton JW, van den Anker JN. Thoughts on "Population pharmacokinetics and relationship between demographic and clinical variables and pharmacokinetics of gentamicin in neonates". Ther Drug Monit. 2003;25(2):256-7. https://doi. org/10.1097/00007691-200304000-00020 (author reply ).

9. Gross JR, Kaplan SL, Kramer WG, Mason EO Jr. Vancomycin pharmacokinetics in premature infants. Pediatr Pharmacol (New York). 1985;5(1):17-22.

10. de Hoog M, Schoemaker RC, Mouton JW, van den Anker JN. Vancomycin population pharmacokinetics in neonates. Clin Pharmacol Ther. 2000;67(4):360-7. https://doi.org/10.1067/ mcp.2000.105353.

11. Frymoyer A, Stockmann C, Hersh AL, Goswami S, Keizer RJ. Individualized empiric vancomycin dosing in neonates using a model-based approach. J Pediatric Infect Dis Soc. 2019;8(2):97104. https://doi.org/10.1093/jpids/pix109.

12. Kumar AA, Burgard M, Stacey S, Sandaradura I, Lai T, Coorey $\mathrm{C}$, et al. An evaluation of the user-friendliness of Bayesian forecasting programs in a clinical setting. Br J Clin Pharmacol. 2019;85(10):2436-41. https://doi.org/10.1111/bcp.14066.

13. Cristea S, Allegaert K, Falcao AC, Falcao F, Silva R, Smits A, et al. Larger dose reductions of vancomycin required in neonates with patent ductus arteriosus receiving indomethacin versus ibuprofen. Antimicrob Agents Chemother. 2019. https://doi. org/10.1128/aac.00853-19.

14. Koch G, Pfister M, Daunhawer I, Wilbaux M, Wellmann S, Vogt JE. Pharmacometrics and machine learning partner to advance clinical data analysis. Clin Pharmacol Ther. 2020;107(4):926-33. https://doi.org/10.1002/cpt.1774. 